BIOKEMISTRI 17(1):33-38 (June 2005)

Available online at http://www. bioline.org. br/bk.

Abstracted online at www.ajol.info/journals/biokem

Printed in Nigeria
An international journal published by the<smiles></smiles>

Orgerian Society for E̊xperimental Siology

\title{
In vitro effects of sodium benzoate on the activities of aspartate and alanine amino transferases, and alkaline phosphatase from human erythrocytes of different genotypes
}

\author{
Michael O. MONANU ${ }^{1 *}$, Augustine A. UWAKWE ${ }^{1}$ and Dike ONWUBIKO ${ }^{2}$ \\ ${ }^{1}$ Department of Biochemistry, University of Port Harcourt, PMB 5323, Port Harcourt, Rivers \\ State, Nigeria \\ ${ }^{2}$ Department of Pathology, School of Clinical Medicine, Abia State University, Aba, Abia State, \\ Nigeria
}

Received 27 February 2004

MS/No BKM/2004/009, (c) 2005 Nigerian Society for Experimental Biology. All rights reserved.

\begin{abstract}
The in vitro effects of varying concentrations sodium benzoate on the activities of aspartate (E.C. 2.6.1.1) and alanine (E.C. 2.6.1.2) aminotransferases (AST and ALT, respectively) and alkaline phosphatase (E.C. 3.1.3.1; abbreviated as ALP) from human erythrocytes of different genotypes (HbAA, HbAS and HbSS) were investigated. The enzyme activities were measured in the absence and presence of five concentrations (from 0.03 to $0.21 \%$ ) of sodium benzoate using erythrocyte preparations from the three genotypes. The results showed significant $(\mathrm{p}<0.05)$ inhibition of the three enzymes from the erythrocytes of HbAA, HbAS and HbSS genotypes by sodium benzoate. The compound at $0.1 \%$ (the recommended concentration used for preservation) significantly decreased $(\mathrm{p}<0.05)$ the activity of HbAA erythrocyte AST to about $93.8 \%$ of the control (no sodium benzoate). HbAS erythrocyte AST showed a significant decrease in activity $(\mathrm{p}<0.05)$ to about $95.0 \%$ of the control, while for HbSS erythrocyte AST activity, a significant decrease $(\mathrm{p}<0.05)$ to $93.8 \%$ of control was observed. For ALT, sodium benzoate $(0.1 \%)$ significantly $(\mathrm{p}<0.05)$ reduced the activity for the HbAA erythrocyte enzyme to $93.3 \%$ of the control (no sodium benzoate). HbAS erythrocyte ALT showed a significant decrease in activity $(\mathrm{p}<0.05)$ at $93.4 \%$ of control, while the activity for HbSS erythrocyte ALT significantly $\mathrm{p}<0.05$ ) decreased to $95.4 \%$ of the control. At $0.1 \%$, sodium benzoate decreased the activity of HbAA erythrocyte ALP significantly $(\mathrm{p}<0.05)$ by $9.7 \%$ of the control. For HbAS erythrocyte ALP, the activity significantly decreased $(\mathrm{p}<0.05)$ to about $91.7 \%$ of control, while for HbSS erythrocyte ALP, a significant decrease $(\mathrm{p}<0.05)$ in the activity to $91.3 \%$ of control was noted. The findings of significant decreases in the activities of AST, ALT and ALP from the different genotypes in the presence of sodium benzoate have far-reaching implications to the use of sodium benzoate as a preservative. It is plausible that the biochemical activities such as amino acid metabolism (amino transferases) and phosphate/lipid metabolism (alkaline phosphatase) performed by these enzymes may be impaired by unregulated consumption of products containing sodium benzoate, suggesting care in the use of this preservative.
\end{abstract}

Key words: sodium benzoate, aminotransferases, erythrocytes, phosphatase

*Author to whom all correspondence should be addressed. E-mail: mikemonanu @ yahoo.com, Tel: 08033122573 


\section{INTRODUCTION}

Benzoic acid and sodium benzoate are widely used as preservatives in several products consumed by human, and while the undissociated benzoic acid is more effective, sodium benzoate is used preferentially as it is about 200 times more soluble

$(1,2,3,4)$. A concentration of about $0.1 \%$ is usually sufficient to preserve a product that has been properly prepared and adjusted to $\mathrm{pH} 4.5$ or below (1). Available literature indicate that the main route of exposure of the general population to benzoic acid or sodium benzoate is likely via foodstuffs that contain the substances naturally or added as antimicrobial agents $(1,5,6)$.

Furthermore, various studies using experimental animals and human subjects revealed some adverse effects due to both chronic and sub-chronic intake of benzoate.

For example, changes in serum parameters and an increased relative liver weight have been described, in addition to histopathological changes of the liver, increased relative kidney weights, and disorders of the central nervous system (convulsions) $(7,8)$.

After oral and dermal uptake, benzoate is metabolized in the liver by conjugation with glycine, resulting in the formation of hippuric acid $(9,10)$. In humans, after oral doses of up to $160 \mathrm{mg} / \mathrm{kg}$ body weight, $75-100 \%$ of the applied dose is excreted as hippuric acid within $6 \mathrm{~h}$ after administration, and the rest within 2-3 days $(11,12,13)$.

Aspartate and alanine amino transferases (AST and ALT, respectively) are key enzymes of amino acid metabolism, a major function of the liver, and they are commonly applied as markers of liver function. They have been reported to have different activity levels in human erythrocytes of $\mathrm{HbAA}, \mathrm{HbAS}$ and $\mathrm{HbSS}$ bloods (14). Also, alkaline phosphatase (ALP), which is present in many tissues of the human body, including kidney, liver, erythrocytes, bone and placenta (15) reportedly showed different activity levels in the different human erythrocyte genotypes (14). ALP is thought to be involved with phosphate metabolism and lipid transport, amongst other functions (15).

The present study investigates the possible effects of this commonly used preservative on the activities of AST, ALT and ALP from human erythrocytes. It is envisaged that the findings will provide some insight on the biochemical impact of such chemical additives used as preservative in various products consumed by humans on the metabolic activities involving the three enzymes studied. It would also give insight to the possible effect of the compound on test results of liver function employing the amino transferases for subjects who had consumed rich sources of benzoate prior to blood sample procurement.

\section{MATERIALS AND METHODS}

Enzyme kits for AST, ALT and ALP assays were obtained from Randox Laboratory, Ltd., San Francisco, U. S. A. Sodium benzoate was purchased from Sigma Chemical Company, St. Louis, U. S. A., while other reagents used were of the highest purity commercially available.

\section{Sample collection and preparation}

Blood was collected by veni-puncture from twelve consenting volunteers, who had fasted for at least eight hours. It was then emptied carefully into lithium heparinized sterile bottles. Electrophoretic genotyping on aliquot of sample for unconfirmed haemoglobin genotype group was then performed (16). The preparation of erythrocytes and haemolyzate followed the procedure described by Beutler (17).

Briefly, the blood sample was centrifuged at $10,000 \mathrm{~g}$ for 5 minutes, washed thrice with 10 volumes of normal saline $(0.9 \%$ $\mathrm{NaCl}$ ) and then diluted 1:20 with a stabilizing solution $(0.27 \mathrm{mM}$ EDTA, $0.27 \mathrm{mM} \quad 2-$ mercaptoethanol, $\mathrm{pH}$ 7.0). The erythrocyte samples obtained were then frozen and thawed for immediate use, or stored in frozen state until used (usually for not more than 10 days). A 0.02 $\mathrm{ml}$ aliquot of the prepared samples (haemolysate) was used for the determination of haemoglobin concentration using Drabkin's solution.

\section{Enzyme assays}

The assay of AST followed a modification of the colorimetric method reported by Varley et al (18). A $0.1 \mathrm{ml}$ aliquot of haemolyzate was added to $0.5 \mathrm{ml}$ substrate mixture containing $100 \mathrm{mM}$ phosphate buffer (pH 7.4), $2 \mathrm{mM}$ 2-oxoglutarate and $100 \mathrm{mM} \mathrm{L-}$ 
Aspartate. Following incubation of the final mixture at $37^{\circ} \mathrm{C}$ for 30 minutes, the reaction was terminated by the addition of $0.5 \mathrm{ml}$ of $1 \mathrm{mM} 2$, 4-dinitro phenyl hydrazine in $1 \mathrm{M}$ hydrochloric acid. After allowing the mixture to stand at room temperature for 20 minutes, $5 \mathrm{ml}$ of $0.4 \mathrm{M}$ sodium hydroxide was added. The absorbance of the final mixture was read, after 5 minutes, at $546 \mathrm{~nm}$ against a blank solution (no incubation at $37^{\circ} \mathrm{C}$, and termination solution added before addition of the haemolysate).

For the test (effect of sodium benzoate), appropriate volumes of standard sodium benzoate solution was added to the substrate mixture to maintain the final reaction volume and give sodium benzoate concentrations of 0 , 0.03, 0.07, 0.10, 0.14 and $0.21 \%$.

Pyruvate solutions of varied millimolar concentrations were used to prepare a standard curve from which AST activities were computed as described by Varley et al (18).

Alanine amino transferase assay was carried out as described for AST except that 200mM DL-alanine replaced L-aspartate in the procedure. The activities of AST and ALT were expressed in international units / $\mathrm{g}$ Haemoglobin.

ALP activity determination followed the procedure reported by Haussament (19), using pnitrophenyl phosphate as substrate in $1 \mathrm{M}$ diethanolamine buffer ( $\mathrm{pH} 9.8)$ containing $0.5 \mathrm{mM}$ $\mathrm{MgCl}_{2}$. A $0.02 \mathrm{ml}$ aliquot of haemolysate was added to $1 \mathrm{ml}$ of the buffered substrate solution and incubated as $37^{\circ} \mathrm{C}$. The absorbance of the reaction mixture was read at $405 \mathrm{~nm}$ at 30second intervals for 3 minutes. For the test (effect of sodium benzoate), similar protocol for AST above was employed. The ALP activity in international units / $\mathrm{g} \mathrm{Hb}$ was calculated from the formula: [enzyme activity] $=(2760 \times \Delta \mathrm{A}) /$ $\mathrm{Hb}$.

\section{Statistical analysis}

This was done by the student's t-test at 95\% confidence level.

\section{RESULTS}

The effects of varying concentrations of sodium benzoate of the activities of erythrocyte AST from the three genotypes are shown in Table 1. For HbAA, the control activity (no sodium benzoate) of $9.81 \pm 0.15$ reduced progressively to $8.40 \pm 0.19$ in the presence of $0.21 \%$ sodium benzoate. The decreases were significant $\quad(\mathrm{p}<0.05)$ from $0.1 \%$ sodium benzoate. The AST activity for $\mathrm{HbAS}$ erythrocytes also decreased progressively from $10.40 \pm 0.18$ (control) to $9.49 \pm 0.19(0.21 \%$ sodium benzoate). Significant decreases $(\mathrm{p}<0.05)$ were seen from concentration of 0.10 $\%$ sodium benzoate. For HbSS erythrocytes, the enzyme activity decreased from $15.35 \pm 0.19$ (control) to $13.22 \pm 0.20(0.21 \%$ sodium benzoate), with significance $(\mathrm{p}<0.05)$ shown from $0.1 \%$ sodium benzoate.

TABLE 1: Effect of sodium benzoate at varying concentrations on aspartate amino transferase from $\mathrm{HbAA}, \mathrm{HbAS}$ and HbSS human erythrocytes.

\begin{tabular}{|l|c|c|c|}
\hline Genotype & {$[\mathrm{NaB}] \%$} & $E(\mathrm{U} / \mathrm{g} \mathrm{Hb})$ & $E(\%$ of control) \\
\hline HbAA & 0.00 & $9.81 \pm 0.15$ & 100.0 \\
$(\mathrm{n}=4)$ & 0.03 & $9.60 \pm 0.17$ & 97.0 \\
& 0.07 & $9.39 \pm 0.19$ & 95.7 \\
& 0.10 & $9.20 \pm 0.15^{*}$ & 93.8 \\
& 0.14 & $9.11 \pm 0.16^{*}$ & 92.9 \\
& 0.21 & $8.40 \pm 0.19^{*}$ & 85.6 \\
\hline HbAS & 0.00 & $10.40 \pm 0.18$ & 100.0 \\
$(\mathrm{n}=4)$ & 0.03 & $10.20 \pm 0.20$ & 98.1 \\
& 0.07 & $10.04 \pm 0.19$ & 96.5 \\
& 0.10 & $9.90 \pm 0.30^{*}$ & 95.2 \\
& 0.14 & $9.87 \pm 0.21^{*}$ & 95.0 \\
& 0.21 & $9.49 \pm 0.19^{*}$ & 91.2 \\
\hline \multirow{3}{*}{ HbSS } & 0.00 & $15.35 \pm 0.19$ & 100.0 \\
$(n=4)$ & 0.03 & $15.18 \pm 0.22$ & 98.8 \\
& 0.07 & $14.81 \pm 0.21$ & 96.5 \\
& 0.10 & $14.40 \pm 0.15^{*}$ & 93.8 \\
& 0.14 & $13.76 \pm 0.19^{*}$ & 89.6 \\
& 0.21 & $13.22 \pm 0.20^{*}$ & 86.1 \\
\hline
\end{tabular}

Data represent mean $\pm S D$ for duplicate determinations.

$[\mathrm{NaB}]=$ concentration of sodium benzoate; $E=$ enzyme activity

* significantly different $(p<0.05)$ from control (no sodium benzoate)

The results of the determinations of the effects of varying concentrations of sodium benzoate on ALT are shown in Table 2. The enzyme activity in the absence of sodium benzoate for HbAA erythrocyte was $5.36 \pm 1.0$. This progressively decreased to $4.64 \pm 0.01$ at $0.21 \%$ sodium benzoate. This inhibitory effect was significant $(\mathrm{p}<0.05)$ from $0.1 \%$ sodium benzoate. For HbAS erythrocyte, the enzyme activity decreased progressively from $5.12 \pm$ 0.11 (control) to $4.48+0.11$ at $0.21 \%$ sodium benzoate. This was significant $(\mathrm{p}<0.05)$ from 0.1 $\%$ sodium benzoate. The activity of $\mathrm{HbSS}$ erythrocyte decrease from $7.62 \pm 0.11$ (control) to $7.11 \pm 0.12$ at $0.21 \%$ sodium benzoate. This 
decrease was significant $(\mathrm{p}<0.05)$ from $0.1 \%$ sodium benzoate.

TABLE 2: Effects of sodium benzoate at varying concentrations on alanine amino transferase from $\mathrm{HbAA}, \mathrm{HbAS}$ and HbSS human erythrocytes.

\begin{tabular}{|l|c|c|c|}
\hline Genotype & {$[\mathrm{NaB}] \%$} & $\mathrm{E}(\mathrm{U} / \mathrm{g} \mathrm{Hb})$ & E (\% of control) \\
\hline $\mathrm{HbAA}$ & 0.00 & $5.36 \pm 0.10$ & 100.0 \\
$(\mathrm{n}=4)$ & 0.03 & $5.14 \pm 0.11$ & 95.9 \\
& 0.07 & $5.12 \pm 0.09$ & 95.5 \\
& 0.10 & $5.00 \pm 0.08^{*}$ & 93.3 \\
& 0.14 & $4.80 \pm 0.09^{*}$ & 89.6 \\
& 0.21 & $4.64 \pm 0.10^{*}$ & 86.6 \\
\hline $\mathrm{HbAS}$ & 0.00 & $5.12 \pm 0.11$ & 100.0 \\
$(\mathrm{n}=4)$ & 0.03 & $5.00 \pm 0.11$ & 97.7 \\
& 0.07 & $4.88 \pm 0.09$ & 95.3 \\
& 0.10 & $4.78 \pm 0.10^{*}$ & 93.4 \\
& 0.14 & $4.64 \pm 0.09^{*}$ & 90.6 \\
& 0.21 & $4.48 \pm 0.11^{*}$ & 87.5 \\
\hline \multirow{3}{*}{$\mathrm{HbSS}$} & 0.00 & $7.62 \pm 0.11$ & 100.0 \\
$(\mathrm{n}=4)$ & 0.03 & $7.49 \pm 0.12$ & 98.3 \\
& 0.07 & $7.37 \pm 0.11$ & 96.7 \\
& 0.10 & $7.27 \pm 0.10^{*}$ & 95.4 \\
& 0.14 & $7.11 \pm 0.09^{*}$ & 93.3 \\
& 0.21 & $7.11 \pm 0.12^{*}$ & 93.3 \\
\hline
\end{tabular}

Data represent mean $+S D$ for duplicate determinations

$[\mathrm{NaB}]=$ concentration of sodium benzoate; $E=$ enzyme activity

* significantly different ( $p<0.05$ ) from control (no sodium benzoate)

TABLE 3: Effects of sodium benzoate at varying concentrations on alkaline phosphatase from $\mathrm{HbAA}, \mathrm{HbAS}$ and HbSS human erythrocytes.

\begin{tabular}{|l|c|c|c|}
\hline Genotype & {$[\mathrm{NaB}] \%$} & $\mathrm{E}(\mathrm{U} / \mathrm{g} \mathrm{Hb})$ & E (\% of control) \\
\hline $\mathrm{HbAA}$ & 0.00 & $84.18 \pm 2.80$ & 100.0 \\
$(\mathrm{n}=4)$ & 0.03 & $82.00 \pm 2.70$ & 97.4 \\
& 0.07 & $77.28 \pm 2.77$ & 91.8 \\
& 0.10 & $76.00 \pm 1.90^{*}$ & 90.3 \\
& 0.14 & $72.45 \pm 2.65^{*}$ & 86.1 \\
& 0.21 & $67.62 \pm 2.57^{*}$ & 80.3 \\
\hline $\mathrm{HbAS}$ & 0.00 & $67.62 \pm 1.90$ & 100.0 \\
$(\mathrm{n}=4)$ & 0.03 & $65.00 \pm 1.85$ & 97.7 \\
& 0.07 & $63.48 \pm 1.88$ & 95.3 \\
& 0.10 & $62.00 \pm 1.80^{*}$ & 93.4 \\
& 0.14 & $60.70 \pm 1.98^{*}$ & 90.6 \\
& 0.21 & $55.20 \pm 1.91^{*}$ & 87.5 \\
\hline \multirow{2}{*}{$\mathrm{HbSS}$} & 0.00 & $65.71 \pm 1.90$ & 100.0 \\
$(\mathrm{n}=4)$ & 0.03 & $63.00 \pm 1.89$ & 95.9 \\
& 0.07 & $61.33 \pm 1.90$ & 93.3 \\
& 0.10 & $60.00 \pm 1.50^{*}$ & 91.3 \\
& 0.14 & $56.90 \pm 1.85^{*}$ & 86.6 \\
& 0.21 & $49.19 \pm 1.88^{*}$ & 73.3 \\
\hline
\end{tabular}

Data represent mean $\pm S D$ for duplicate determinations

$[\mathrm{NaB}]=$ concentration of sodium benzoate; $E=$ enzyme activity

* significantly different $(p<0.05)$ from control (no sodium benzoate)

Table 3 shows the effect of sodium benzoate on the ALP activities of the different erythrocytes. The enzyme activity for HbAA erythrocyte decreased from $84.18 \pm 2.80$ (control) to $67.62 \pm 2.57 \quad(0.21 \%$ sodium benzoate), and this was significant $(\mathrm{p}<0.05)$ from $0.10 \%$ sodium benzoate. For $\mathrm{HbAS}$ erythrocyte, a decrease from $67.62 \pm 1.90$ (control) to $55.20 \pm 1.91(0.21 \%$ sodium benzoate), which was significant $(\mathrm{p}<0.05)$ from $0.1 \%$ sodium benzoate was recorded. The HbSS erythrocyte showed decrease in enzyme activity from $65.71 \pm 1.90$ (control) to $49.19 \pm 1.99$ (0.21\% sodium benzoate). Significant decreases $(\mathrm{p}<0.05)$ occurred from $0.1 \%$ sodium benzoate.

\section{DISCUSSION}

As shown in Table 1, sodium benzoate at the concentrations used inhibited the activity of AST for HbAA, HbAS and HbSS erythrocytes. This inhibition was significantly different $(\mathrm{p}<0.05)$ for the three genotypes at 10 , 14 and $21 \mathrm{mM}$ concentrations when compared with control (absence of sodium benzoate). Similar trends were obtained for ALT and ALP, as shown in Tables 2 and 3, respectively. It is notable that the inhibitions by sodium benzoate were significant at the recommended maximal concentration in industrial products preservation of $0.1 \%$ (1). Furthermore, based on the enzyme activities relative to the control, no differences were apparent between the effects of sodium benzoate at the various concentrations for the HbAA, HbAS and HbSS genotypes.

While the mode of inhibition was not determined in this study, it is possible that for the amino transferases, sodium benzoate could be acting in a manner similar to proxazole, another antiseptic and antipyretic compound (20). It had been suggested that an amide bond forms between an aminosyl group of the amino transferases and a carboxyl group of proxazole citrate, thus preventing the enzyme from interacting with its coenzyme, pyridoxal phosphate (20). It has been suggested that aromatic compounds such as phenylalanine competitively inhibit transamination between aspartate and glutamate (21). The inhibition of the amino transferases by sodium benzoate could be explained by the possible involvement of its carboxyl function as well as the aromatic ring in interacting with the amino transferase in manners similar to proxazole citrate.

There is no plausible explanation for the inhibitory action of sodium benzoate of ALP. This enzyme is a $\mathrm{Zn}^{2+}$-metalloprotein and perhaps the action of sodium benzoate noted in this study could be related to the interaction 
between this compound and the metal. Sodium benzoate, being a foreign compound, is actively metabolized (detoxicated) in the liver and in chronic doses may present a load to the liver thereby result in liver malfunction.

The inhibitory potential of sodium benzoate noted in this in vitro study is interesting given the earlier reports on the possible effect of chronic doses on sizes of organs like the liver $(7,8)$. However, bioavailability, variations in effective concentration in the body as well as individual's rate of metabolism and excretion, all affect the amount of the ingested compound that could affect these enzymes activities in vivo (22). Nonetheless, our findings suggest that caution is needed in the use of sodium benzoate as a preservative in the various products consumed by humans. This would help in avoiding possible complications in the metabolic activities involving the three enzymes, AST, ALT and ALP. Also, care is needed when interpreting results of liver function test done by assessing the levels of AST and ALP in serum samples as prior exposure to high levels of sodium benzoate could produce anomalous results through the inhibitory effect seen in this study.

\section{REFERENCES}

1. Chipley, J. R. (1983) Sodium benzoate and benzoic acid. In: Antimicrobials in foods A. L. Branen \& P. M. Davidson (eds.), pp. 11-35. Marcel Decker, New York.

2. Baldwin, E. A., Nisperos-Carriedo, M. O. and Baker, R. A. (1995) Use of edible coatings to preserve quality of lightly (and slightly) processed products. Critical Revs. in Food Sci. Nutri. 35:509-524.

3. Sainio, E. and Kanerva, L. (1995) Contact allergens in toothpastes and a review of their hypersensitivity. Contact dermatitis, 33:100-105.

4. Ishida, H. (1996) Levels of preservatives in toothpastes and possibility of their intake during brushing of teeth. $J$. of Food Hygiene Society of Japan. 37:234239.

5. Freedman, B. J. (1977) Asthma induced by sulphur dioxide, benzoate and tartrazine contained in orange drinks. Clinical allergy 7:407-415.

6. Villanueva, M. B. G., Jonai, H., Kanno, S. and Takeuchi, Y. (1994) Dietary sources and background levels of hippuric acid in urine: Comparison of Philippine and Japanese levels. Industrial Health 32:239-249.

7. Sodemoto, Y. and Enomoto, M. (1980) Report of carcinogenesis bioassay of sodium benzoate in rats: absence of carcinogenicity of sodium benzoate in rats. J. Environ. Path. Toxico. 4:87-95.

8. Fujitani, T. (1993) Short-term effect of sodium benzoate in F344 rats and $\mathrm{B}_{6} 3 \mathrm{~F}_{1}$ mice. Toxicology Letters 69:171-179.

9. Feldmann, R. J. and Maibach, H. I. (1970) Absorption of some organic compounds through the skin in man. J. of Invest. Dermatol., 54:399-404.

10. Feillet, F. and Leonard, J. V. (1998) Alternative pathway therapy for urea cycle disorders. J. of Inherited Metabolic Disease, Suppl. 21:101-111.

11. Kubota, K., Horai, Y., Kushida, K. and Ishizaki, T. (1988) Determination of benzoic acid and hippuric acid in human plasma and urine by high performance liquid chromatography. J. of Chromatography, 425(1):67-75.

12. Fujii, T., Omori, T., Tagucji, T. and Ogata, M. (1991) Urinary excretion of hippuric acid after administration of sodium benzoate (biological monitoring 1). J. Food Hygiene Society of Japan, 32(3): 177-182.

13. Kubota, K. and Ishizaki, T. (1991) Dosedependent pharmacokinetics of benzoic acid following oral administration of sodium benzoate to humans. Eur. J. Clin. Pharmacol. 41:363-368.

14. Onwubiko, D., Uwakwe, A. A. and Monanu, M. O. (2003) Activities of Aspartate (E. C. 2.6.2.2 and alanine (E. C. 2.6.1.2) Transaminases and Alkaline phosphatase (E. C. 3.2.3.1) in human erythrocytes from different genotypes. Global J.Pure \& Appld. Sciences 9: 365-368. 
15. McComb, R. B., Bowers, G. N. (Jr.), and Posen, S. (1979) Alkaline phosphatase. In: Biological Chemistry ( $3^{\text {rd }}$ ed.). B. Milner (ed.), pp. 465 - 468 Planum Press, New York.

16. Henry, R. J., Cannon, D. C. and Winkelman, J. W. (1974) In: Clinical Chemistry: Principle and Techniques, $\left(2^{\text {nd }}\right.$ ed.). R. J., Henry (ed.) editor, pp. $873-888,1182-1185$. Harper \& Row, New York.

17. Beutler, R. (1984) Red cell metabolism. In: A manual of biochemical methods $\left(3^{\text {rd }}\right.$ ed. $)$, p. 78 - 83. Grime \& Stratton, New York.

18. Varley, H., Gowenlock, A. H. and Bell, M. (1980) Practical Clinical Biochemistry, Vol. 1 (5 $5^{\text {th }}$ ed.), pp. 741742, 892-908. W. Heinemann, London.
19. Haussament, T. U. (1977) Quantitative determination of serum alkaline phosphatase. Clin. Chem. Acta. 35: 271273.

20. Skidmore, I. F. and Whitehouse, M. W. (1965) Biochemical properties of antiinflammatory drugs. Biochemical Pharmacology, 15: 17 - 24.

21. Shrawder, E. and Martinez-Carrion, $M$. (1972) Evidence of phenylalanine transferase activity in isoenzymes of Aspartate transaminase. J. Biol. Chem. 247:2486-2492.

22. Grem, Y., Csanady, G., Filser, J. G., Kreuzer, P., Schwartz, L., Wolf, T. and Werner, S. (1995). Biomarkers as Tools in Human Risk Assessment. Clin. Chem. 41:1804-1808. 